\title{
ESPAÇOS DE ISOLAMENTO NOS ROMANCES DE MIA COUTO
}

Everton Fernando Micheletti ${ }^{1}$

RESUMO: Este artigo propõe analisar o isolamento como tema recorrente nos romances de Mia Couto, tanto em relação às personagens, individualmente, como pelas vilas e aldeias, geralmente em contraponto aos grandes centros urbanos. Entre as razões para o isolamento, estão as consequências do colonialismo e da guerra posterior à Independência de Moçambique, em que estão implicadas as questões entre campo e cidade, local e global, tradição e modernidade.

ABSTRACT: This paper aims to analyze the isolation as a recurrent theme in the works of Mia Couto, both related to the characters, individually, through the towns and villages, often in contrast to the large urban centers. Among the reasons for the isolation are the consequences of colonialism and the war after Independence of Mozambique, in which are implicated the issues between country and city, local and global, tradition and modernity.

PALAVRAS-CHAVE: Mia Couto; Literatura moçambicana; Romance; Espaço; Isolamento

KEYWORDS: Mia Couto; Mozambican literature; Novel; Space; Isolation

1 Doutorando do Programa de Estudos Comparados de Literaturas de Língua Portuguesa (DLCV-USP), desenvolvendo a pesquisa: "Os (des)caminhos da nação: um estudo comparado do espaço em Terra sonâmbula e Mãe, Materno Mar”. 


\section{INTRODUÇÃO}

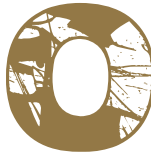

isolamento pode ser encontrado na maior parte dos romances de Mia Couto, como tema central ou entre os motivos que compõem o enredo. Pode ser considerado de dois modos principais: há o isolamento individual, de uma ou de poucas personagens, e o de comunidades inteiras, como as aldeias e vilas, geralmente em contraponto aos grandes centros urbanos. Estão implicadas, nesses casos, as tensões entre campo e cidade, local e global, tradição e modernidade, com o olhar voltado ao interior do país, visto que são poucas as narrativas do autor que têm a capital Maputo como espaço.

De maneira geral, o isolamento decorre das consequências do colonialismo e da guerra posterior à Independência de Moçambique. De forma mais específica, há as questões sobre a situação da mulher e dos idosos na sociedade, os administradores do governo ligados a negócios contrários ao projeto do país, entre outros casos. Como metonímias da nação, as aldeias e vilas refletem os problemas sociais, apontando para um "ilhamento" do país em relação ao contexto global. Desse modo, são apontadas e analisadas a seguir algumas das situações e razões para o isolamento, primeiramente com um panorama de vários romances para demonstrar que se trata de um tema recorrente em suas obras, depois com ênfase em Terra sonâmbula.

\section{O ISOLAMENTO COMO TEMA RECORRENTE NOS ROMANCES DE MIA COUTO}

A protagonista de $O$ outro pé da sereia, Mwadia, "que tinha corpo de rio e nome de canoa", vivia isolada em uma aldeia chamada de Antigamente, "nesse lugar de que se esqueceram os caminhos"(COUTO, 2006, p. 15-16), até que vai para a Vila Longe. Nesse romance, os nomes dos lugares já trazem a ideia do isolamento, não apenas espacial - Vila Longe -, mas, também, temporal - Antigamente. Em $O$ último voo do flamingo, a narrativa se passa em Tizangara, descrita como a vila que "que foi engolida pelo mato", "tão abandonada que até as coisas fo- 
ram perdendo seus nomes" (COUTO, 2005, p. 67)2. As outras descrições reforçam o abandono, o lugar parece que está se desfazendo, a "vila parecia em despedida do mundo" (COUTO, 2005, p. 109), em um processo inverso ao livro bíblico do Gênesis, quando o mundo se fazia por meio do nomear. No desfecho, o lugar desaparece, até "tudo ser neblina, tudo nuveado" (COUTO, 2005, p. 219).

Em contraponto, no romance Antes de nascer o mundo, o isolamento ocorre quando o protagonista decide fundar uma nova sociedade, que ele nomeia como "Jesusalém". Silvestre Vitalício decide afastar-se da cidade, leva os filhos para um lugar distante e impede a presença de mulheres. Eles se instalam "num abandonado acampamento de caçadores", notando que em "redor, a guerra tornara tudo vazio, sem sombra de humanidade. Até os animais eram escassos. Abundava apenas o bravio mato onde, desde havia muito, nenhuma estrada se desenhava" (COUTO, 2009, p. 20).

Com a temática do conflito pós-Independência e dos primeiros anos do processo de paz, A varanda do frangipani tem como espaço uma antiga fortaleza colonial transformada em asilo para idosos. Durante a guerra, "o asilo esteve isolado do resto do país... cortara relações com o universo", sendo que as "rochas, junto à praia, dificultavam o acesso por mar" e as "minas, do lado interior, fechavam o cerco" (COUTO, 2008, p. 20). O acesso ao local só era possível pelo ar, de helicóptero. $O$ insulamento ${ }^{3}$ evidencia a desordem social, em que os mais velhos são abandonados pela "nova" sociedade, como um deles reflete: "neste lugar, a gente definha, morrendo tão lentamente que nem damos conta. A velhice o que é senão a morte estagiando em nosso corpo?" (COUTO, 2008, p. 49).

2 Grifos do autor nessa e nas demais citações.

3 Os termos "insulamento" e "ilhamento" são utilizados por Osman Lins em sua análise do espaço nas obras de Lima Barreto. Não se referem a ilhas "reais" ou isolamentos em absoluto, mas a processos em que uma ou algumas personagens são isoladas pela dificuldade de comunicação, pela inoperância de seus atos sobre o próximo e sobre o meio, de modo que Lins considera algumas personagens como "figuras insulares" e afirma que há romances dominados pelo "tema do insulamento". (LINS, 1976, p. 31-48). 
As vilas e aldeias, no entanto, não são lugares totalmente inacessíveis, o isolamento decorre, na maioria das vezes, do abandono dos administradores, do processo de decadência que se intensifica com a guerra e, também, da modernidade que não chega por completo. A Vila Cacimba de Venenos de Deus, Remédios do Diabo bem exemplifica esse aspecto do isolamento. Como o nome indica, é como se o lugar não pudesse ser visto, como se fosse desaparecer ou que fosse, mesmo, um lugar de mentira. Devido a uma epidemia e a sensação de estarem desamparados pelo governo, uma personagem considera o lugar como "um barco incendiado: ou morriam na água ou acabariam devorados pelas chamas" (COUTO, 2010, p. 47).

A temática do isolamento relaciona-se à situação das mulheres na sociedade em $A$ confissão da leoa, romance que tem como espaço a aldeia de Kulumani, onde estariam acontecendo ataques de leões. A protagonista, Mariamar, vendo-se "ilhada", impedida de sair de casa pelo pai, decide fugir por um rio, como ela descreve: "Dizem que este rio, mais longe, atravessa a cidade. Duvido. Este meu rio que nem português fala, este rio repleto de peixes que só conhecem os seus nomes em shimakonde, não acredito que deixem entrar este rio na cidade." (COUTO, 2012, p. 49). Sua viagem, no entanto, não prossegue: "a canoa estancou e, por mais que me esforce, não saio do sítio" (COUTO, 2012, p. 54). É resgatada, depois, e levada de volta à aldeia.

Mariamar, Mwadia e Farida de Terra sonâmbula são mulheres que enfrentam o meio social hostil, sendo impelidas ao isolamento. Há, na perspectiva de Mariamar, também, a oposição entre campo e cidade, em que se tem a tensão entre as tradições e a suposta modernidade da capital. Esse aspecto aproxima-se do que afirma Williams:

[...] é significativo que a imagem comum do campo seja agora uma imagem do passado, e a imagem comum da cidade, uma imagem do futuro. Se as isolarmos deste modo, fica faltando o presente. A ideia do campo tende à tradição, aos costumes humanos e naturais. A ideia da cidade tende ao progresso, à 
modernização, ao desenvolvimento. Assim, num presente vivenciado enquanto tensão, usamos o contraste entre campo e cidade para ratificar uma divisão e um conflito de impulsos ainda não resolvidos... (WILLIAMS, 1990, p. 397)

Nos romances de Couto, há esse conflito, sendo o que marca a vila de Um rio chamado tempo, uma casa chamada terra, de nome Ilha Luar-do-Chão. É descrita como separada da "cidade" por um rio, cujas "águas, porém, afastam mais que a sua própria distância. Entre um e outro lado reside um infinito." (COUTO, 2003, p. 18). A temática do insulamento é marcada, nesse romance, pelas águas que dividem espaço-temporalmente a cidade e a vila, em que a segunda passa pelo processo de degradação:

[...] a vila é demasiado rural, falta-lhe a geometria dos espaços arrumados. Lá estão os coqueiros, os corvos, as lentas fogueiras que começam a despontar. As casas de cimento estão em ruína, exaustas de tanto abandono. Não são apenas casas destroçadas: é o próprio tempo desmoronado. [...] Dói-me a ilha como está, a decadência das casas, a miséria derramada pelas ruas. Mesmo a natureza parece sofrer de mau-olhado. Os capinzais se estendem secos, parece que empalharam o horizonte. À primeira vista tudo definha. No entanto, mais além, à mão de um olhar, a vida reverbera, cheirosa como um fruto em verão: enxames de crianças atravessam os caminhos, mulheres dançam e cantam, homens falam alto, donos do tempo. (COUTO, 2003, p. 27-28)

A deterioração abrange o ambiente social e o natural, em que se notam as marcas históricas da guerra no lugar. Esse aspecto remete a Bakhtin sobre "ler o tempo" no espaço, "ler os indícios do curso do tempo em tudo", em que "os visíveis indícios complexos do tempo histórico... são vestígios visíveis da criação do homem, vestígios de suas mãos e da sua inteligência: cidades, ruas, casas, obras de arte, técnicas, 
organizações sociais, etc." (BAKHTIN, 2011, p. 225). Mas, nesse caso, são vestígios da destruição. Na "leitura" das ruínas da Ilha Luar-do-Chão, há certa melancolia, mas que não põe fim à esperança, visto que a "vida reverbera". A literatura de Couto, portanto, não tende ao desencanto total e irreversível, há projeções de um futuro positivo, a possibilidade de recuperação. $\mathrm{O}$ isolamento recorrente expõe um problema que pode e precisa ser superado.

\section{ESPAÇOS INSULARES EM TERRA SONÂMBULA}

Em Terra sonâmbula, o insulamento ocorre em veículos abandonados, o ônibus em que passam a viver Tuahir e Muidinga, o navio encalhado onde se isola Farida. Segundo Leite, os veículos são "ilhas" em que se desenvolve a afetividade entre as principais personagens. No navio, Kindzu conhece Farida,"faz a iniciação amorosa e ganha de novo ânimo para viver"; no ônibus, Tuahir e Muidinga "reaprendem... outro tipo de amor, o de pai para filho, o de mais velho para mais novo" (LEITE, 2012, p. 74). Enquanto há o espaço externo com a destruição da guerra pós-Independência, os veículos são espaços internos de intimidade e proteção, ainda que precários.

Farida, Tuahir e Muidinga, portanto, são personagens sem casa, sem a proteção dessa "área inviolável de paz" (BOLLNOW, 1961, p. 33). O lar, segundo alguns estudos geográficos, é tido como "a essência do lugar", de modo que "todas as outras experiências de lugar são de alguma forma comparadas com nossa experiência de lar" (RELPH, 2012, p. 29). É considerado "um lugar central por excelência e em toda a sua grandeza", pois é, entre outros aspectos, "um refúgio íntimo, trançado por laços de afinidades e significados... impregnado por experiências do passado e do presente" (MELLO, 2012, p. 38). Desse modo, não ter um lar torna a experiência espacial mais terrível para as personagens.

Tuahir e Muidinga se deslocam pela estrada tomada pela morte; quando chegam ao ônibus destruído, de certa forma o transformam em casa, mas que não chega a compor-se num espaço totalmente 
tranquilo, pois havia os mortos e a escuridão impedindo a formação de um lar. Eles fazem algumas saídas pelos arredores e defrontam-se com os perigos do espaço externo. Desse modo, eles vivem a dualidade do espaço, em que "segurança e perigo pertencem ao homem" e "a vida se desenvolve na tensão entre espaço externo e interno" (BOLLNOW, 1961, p. 34). Ao final, Muidinga termina sozinho, no mar, após despedir-se de Tuahir, e conclui a leitura dos cadernos de Kindzu, em um isolamento que gera a reflexão depois de recuperar sua identidade como Gaspar, o filho desaparecido de Farida.

O insulamento de Farida, por sua vez, ocorre no mar, em um navio encalhado. A decisão de ficar sozinha no veículo abandonado se deve à sua difícil experiência em terra. Primeiramente, enfrentou as tradições ancestrais de seu povo por ser filha gêmea, o que se considerava sinal de desgraça. Vendo-se obrigada a partir, se "lançou na estrada, sem nada senão as roupas" (COUTO, 2007, p. 73). Acolhida por um casal de portugueses, sofre a violência sexual e engravida.

Farida se vê sem um lugar, não podendo voltar à aldeia onde nasceu nem permanecer na casa dos portugueses que a haviam adotado. A gravidez torna-se um novo problema, pois o filho seria branco, considerado albino. Após dar à luz, Farida deixa o filho na igreja da Missão e não o vê mais. Como a terra torna-se para ela um "não-lugar", segundo expressão de Fonseca e Cury (2008, p. 116), Farida se isola no navio e observa o farol na esperança de partir para longe de seu país, enquanto espera reencontrar o filho. Ao conhecer Kindzu, ela aponta para uma ilha e explica:

- Vês aquelas sombras lá? É um pequenita ilha. Nessa ilhinha está um farol. Já não trabalha, se cansou. Quando esse farol voltar a iluminar a noite, os donos deste barco vão poder encontrar o caminho de volta. A luz desse farol é a minha esperança, apagando e acendendo tal igual a minha vontade de viver. (COUTO, 2007, p. 83)

Apesar de isolada, Farida desenvolve uma ação modificadora do enredo, pois a relação amorosa com Kindzu o leva a um desvio de per- 
curso, indo em busca de Gaspar. Trata-se de um insulamento diferente do observado por Lins nas obras de Lima Barreto, quando as personagens parecem isoladas por não afetarem ou mudarem o destino umas das outras (LINS, 1976, p. 37). Farida permanece no navio, faz Kindzu alterar sua rota e espera, para, depois, ir a um outro lugar. $O$ farol torna-se, então, uma "concretização" do sentimento de esperança no espaço externo.

Semelhante a Mwadia que tinha nome de canoa, o nome de Farida advém do farol, a personagem se caracteriza pela relação que tem com o espaço. Assim, Farida concentra o olhar no farol como se ela própria fosse a luz apagada com a esperança de reacender. Em seu estudo sobre o espaço, Lins pergunta onde "acaba a personagem e começa o seu espaço?", respondendo que a "separação começa a apresentar dificuldades quando nos ocorre que mesmo a personagem é espaço", que "suas recordações e até as visões de um futuro feliz, a vitória, a fortuna, flutuam em algo que, simetricamente ao tempo psicológico, designaríamos como espaço psicológico" (LINS, 1976, p. 69). Farida tem sua vida como aquele espaço, vivendo entre a terra com suas tradições e a guerra, tendo o mar como uma saída.

Há uma intensificação da experiência espacial com o abandono provocado pela guerra. Vecchi relaciona o problema do "espaço no tempo do abandono" à disputa de poder, afirmando que, embora não se "exclua a dimensão temporal" que se "articula na problemática do poder e das suas estruturas justamente históricas", a ênfase recai no espaço contemporaneamente porque nele é que há algo do poder "camuflado", "a matriz escondida da política atual", o silêncio como "o som da exclusão..." (VECCHI, 2009, p. 172-177). Tuahir, Muidinga e Farida, principalmente quando ela é perseguida pela administração em Matimati, são os excluídos espacialmente devido ao poder - eles, no campo de refugiados e, depois, no ônibus; ela, no navio. Ao mesmo tempo, Farida quer reverter o abandono do filho, que havia deixado na igreja, mas não consegue reencontrá-lo. Sem lugar, portanto, sem ter para onde ir no labirinto de seu país, o navio "materializa" aquilo que Farida vive, quer partir mas não consegue. 
Não ter lugar leva a outros problemas, como a "perda" da identidade. Farida foi afastada de seu povo por ser gêmea e é perseguida pela administração do governo da nação independente, logo, não consegue ser parte da "velha" nem da "nova" identidade. No entanto, ainda mantém um vínculo com aquela terra pelo filho, talvez aí esteja a resposta para a questão da identidade nacional moçambicana, sua formação depende das novas gerações. Nesse sentido, Vieira faz uma "leitura simbólica" de Muidinga/Gaspar "como representante do povo moçambicano e do caminho que este terá de percorrer em direção à paz", visto que ele é "fruto de uma violação, agressão frequentemente associada ao colonialismo, a sua existência representa a fusão entre África e Europa, que é a realidade do território" (VIEIRA, apud MORAES, 2009, p. 51). Para a autora, o menino "reflecte a esperança da união destas duas culturas que a geração de Kindzu e Farida não pode conciliar" (VIEIRA, apud MORAES, 2009, p. 51).

O caso de Farida corresponde ao que afirma Lins, que "o espaço, no romance, tem sido... tudo que, intencionalmente disposto, enquadra a personagem e que, inventariado, tanto pode ser absorvido como acrescentado pela personagem", não sendo apenas "pano de fundo, ou seja, estático, fora das personagens, descrito como um universo de seres inanimados e opacos" (LINS, 1976, p. 72). O sentimento de esperança, algo de sua interioridade, materializa-se no farol, no espaço externo. Com tudo que lhe acontece, o espaço parece exercer uma "força" sobre Farida, impelindo-a ao isolamento no navio. Como o "espaço-força" de que trata Gullón, o espaço não é simplesmente onde os objetos estão e, sim, "ativo, tendencioso, capaz de obcecar, alucinar e destruir seu habitante" (GULLÓN, 1980, p. 17).

Em Terra sonâmbula, a "força" que leva ao insulamento decorre principalmente das ações humanas, como nas cerimônias tradicionais e na guerra. Tuahir, Muidinga e Farida parecem estar em um labirinto, deslocam-se sem haver saída para os obstáculos que encontram, até restarem os veículos/ilhas. Ao final, apenas o menino sobrevive, indicando que a mudança futura depende da nova geração. 


\section{CONSIDERAÇÕES FINAIS}

Nos vários romances de Couto, os isolamentos individuais e coletivos se devem aos problemas do meio social, principalmente sobre o processo de se fazer a nação após a Independência. No caso das aldeias e vilas, parece haver um abandono do campo em relação à cidade, com as situações precárias não resolvidas pelo governo. Mas vale lembrar que a cidade também tem seus espaços de abandono, como os bairros de periferia, assim como, no contexto global, há as diferenças entre os países desenvolvidos e os subdesenvolvidos. Muitas vezes, as vilas e aldeias das narrativas de Couto são metonímias da nação, um microcosmo da "ilha" de Moçambique.

Em face disso, surgem mais perguntas do que respostas. Seria Moçambique uma nação que se faz de espaços insulares? Seria uma nação insular? Abdala Jr., analisando obras de outros escritores, refere-se à "ilha" como "um espaço aparentemente à margem do sistema" (ABDALA JR., 2007, p. 25). É possível que Couto esteja operando entre as margens e os centros, entre espaços hegemônicos e os não hegemônicos, de que faz parte o conflito entre o local e o global. O próprio conceito de lugar, para algumas perspectivas geográficas, consiste em uma "tensão fundamental que se exerce entre o particular e o universal” (BERDOULAY e ENTRIKIN, 2012, p. 111).

De acordo com Fonseca e Cury há, na literatura de Couto, um conflito entre o local e o universal, em que "cultura e natureza imbricam-se em tensão permanente", sendo que, atravessados "por essa dinâmica, o deslocamento e a errância relacionam-se à perda de referências ao solo natal" (FONSECA e CURY, 2008, p. 99). Embora, pelo lado universal, o deslocamento e a errância sejam característicos do mundo contemporâneo, na África, "as contradições se acirram", pois decorrem "do processo de descolonização tardia", sendo recentes as "marcas indeléveis" do colonialismo, "condicionando as representações da nação e de sua espacialidade fraturada" (FONSECA e CURY, 2008, p. 99).

Por meio dos espaços insulares, Couto não soluciona, antes apre- 
senta o problema a ser enfrentado; deixa entrever, no entanto, uma resposta possível. Como uma das tensões se dá entre tradição e modernidade, a escrita pode ser um dos caminhos "modernos" contra o isolamento. Em Um rio chamado tempo, uma casa chamada terra, por exemplo, são as cartas que mantêm um elo, uma "ponte" entre a velha e a nova geração (COUTO, 2003, p. 126). Na mesma perspectiva, são os cadernos de Kindzu, em Terra sonâmbula, que se fazem "ponte" com Muidinga, da geração seguinte, transformando-se em "páginas de terra" ao final, assim, há a fusão de estórias e História, da escrita e da nação.

Nos romances publicados mais recentemente, $A$ confissão da leoa (2012) e Mulheres de cinzas (2015), as narrativas se organizam estruturalmente por meio de cartas, sendo contemplados diferentes pontos de vista, vários ângulos, para se pensar o país. Nesse contexto, a "ponte", um dos caminhos contra o isolamento, é a escrita. Vale lembrar que Couto tem como fonte as tradições orais, as quais recria, muitas vezes, em suas obras.

\section{REFERÊNCIAS BIBLIOGRÁFICAS}

ABDALA JR., Benjamin. De Voos e Ilhas: Literatura e Comunitarismos. 2. ed. Cotia: Ateliê, 2007.

BAKHTIN, Mikhail M. Estética da Criação Verbal. 6.ed. São Paulo: WMF Martins Fontes, 2011.

BERDOULAY, Vincent e ENTRINKIN, J. Nicholas. Lugar e Sujeito: perspectivas teóricas. In: MARANDOLA JR., Eduardo; HOLZER, Werther; OLIVEIRA, Lívia de (orgs.). Qual o espaço do lugar?: geografia, epistemologia, fenomenologia. São Paulo, Perspectiva, 2012, p. 93-116.

BOLLNOW, Otto Friedrich. Lived-Space. In: Philosophy Today, v.5, n.1/4, Spring 1961, p. 01-08.

COUTO, Mia. Mulheres de cinzas. As areias do imperador: uma trilogia moçambicana, livro 1. São Paulo: Companhia das Letras, 2015.

. A confissão da leoa. São Paulo: Companhia das Letras, 2012. - Venenos de Deus, Remédios do Diabo: as incuráveis vidas de

Vila Cacimba. São Paulo: Companhia das Letras, 2010. 
. Antes de nascer o mundo. São Paulo: Companhia das Letras, 2009.

2008.

. A varanda do frangipani. São Paulo: Companhia das Letras,

. Terra sonâmbula. São Paulo: Companhia das Letras, 2007.

2006.

. O outro pé da sereia. São Paulo: Companhia das Letras, 2005.

. O último voo do flamingo. São Paulo: Companhia das Letras, Companhia das Letras, 2003.

FONSECA, Maria Nazareth Soares e CURY, Maria Zilda Ferreira. Mia Couto: espaços ficcionais. Belo Horizonte: Autêntica, 2008.

GULLÓN, Ricardo. Espacio y Novela. Barcelona: Antoni Bosch, 1980.

LEITE, Ana Mafalda. Oralidades \& escritas pós-coloniais: estudos sobre literaturas africanas. Rio de Janeiro: Ed. UERJ, 2012.

LINS, Osman. Lima Barreto e o espaço romanesco. São Paulo: Ática, 1976. MELLO, João Baptista Ferreira de. O Triunfo do Lugar sobre o Espaço. In: MARANDOLA JR., Eduardo; HOLZER, Werther; OLIVEIRA, Lívia de. (orgs). Qual o espaço do lugar?: geografia, epistemologia, fenomenologia. São Paulo, Perspectiva, 2012, p. 33-68.

MORAES, Anita Martins Rodrigues de. O inconsciente teórico: investigando estratégias interpretativas de Terra Sonâmbula, de Mia Couto. São Paulo: Annablume/FAPESP, 2009.

RELPH, Edward. Reflexões sobre a Emergência, Aspectos e Essência de Lugar. In: MARANDOLA JR., Eduardo; HOLZER, Werther; OLIVEIRA, Lívia de. (orgs). Qual o espaço do lugar?: geografia, epistemologia, fenomenologia. São Paulo, Perspectiva, 2012, p. 17-32.

VECCHI, Roberto. Postscriptum: o espaço no tempo do abandono. In: RAVETTI, Graciela; CURY, Maria Z.; ÁVILA, Myriam (orgs.). Topografias da cultura: representação, espaço e memória. Belo Horizonte: Ed. UFMG, 2009, p. 167-178.

WILLIAMS, Raymond. O campo e a cidade: na história e na literatura. São Paulo: Companhia das Letras, 1990. 